\title{
A comparative analysis of precipitation estimation methods for streamflow prediction
}

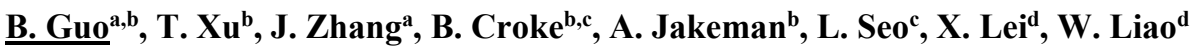 \\ ${ }^{a}$ Beijing Key Laboratory of Resource Environment and Geographic Information System, Capital Normal \\ University, Beijing 100048, China \\ ${ }^{b}$ Integrated Catchment Assessment and Management (iCAM) Centre, The Fenner School of Environment and \\ Society, The Australian National University, Australian Capital Territory, Australia \\ ${ }^{c}$ Mathematical Sciences Institute, The Australian National University, Australian Capital Territory, \\ Australia \\ ${ }^{d}$ China Institute of Water Resources \& Hydropower Research State Key Laboratory of Simulation and \\ Regulation of Water Cycle in River Basin, Beijing 100038, China \\ Email: guobinbin@,126.com
}

\begin{abstract}
Surface hydrologic models are widely used for streamflow prediction, forecasting and for understanding hydrologic processes. They are also an important tool for contributing to the resolution of wider resource and environmental issues, providing information to support policies and decisions for water resource management. Precipitation is a key input to hydrologic models and is however also the major source of predictive uncertainty. Whilst station-based observed precipitation data can be adequate for hydrologic modelling in small catchments, they may not be sufficient for large catchments, in particular for large catchments with a mountainous terrain. Areal estimation of precipitation is a potential option to provide more precise precipitation input to models for large catchments. Conventionally, for areal precipitation estimation, station-based precipitation data are interpolated across the model domain using various methods, including Spline fitting, Inverse Distance Weighting (IDW) and the classical Thiessen Polygon, which are among the more popular and commonly used methods. Different precipitation interpolation methods will affect the spatial and temporal variability of areal precipitation inputs, resulting in different uncertainties when used to help calibrate a surface hydrologic model. This paper investigates the effect of the above three types of precipitation interpolation methods (ANUSPLIN surface, IDW surface and Thiessen polygon) on streamflow predictions. The Chaohe basin located in northern China is selected as the study area. It is an important headwater of the Miyun Reservoir which provides drinking water to Beijing and surrounding townships. Three lumped, surface hydrologic models (GR4J, IHACRES and Sacramento) are selected to study the accuracy and predictive uncertainty of these three types of precipitation interpolation on daily streamflow. The models were calibrated separately using discharge observations from three gauges in the basin. The results show that the ANUSPLIN surface interpolation performs the best overall under various combinations of conditions. The IDW surface also performs well in the upper and middle basin but the Thiessen polygon is inferior to the other two methods. The comparison of the three hydrologic models shows that IHACRES and Sacramento perform better than GR4J. The best combination is areal rainfall estimated using the ANUSPLIN derived surface with the IHACRES model in the case study catchments, though the Sacramento model is a close second.
\end{abstract}

Keywords: Areal precipitation, ANUSPLIN, IDW, Thiessen polygon, hydrologic prediction 


\section{INTRODUCTION}

Hydrological models are essential tools for understanding processes of the hydrological cycle and providing reliable information for sustainable water resources management in general and such operational issues as flood forecasting. Precipitation is the main driving factor of hydrological processes and is a key input to hydrological models. Traditionally, station-based observational precipitation data from observation network stations have been used as the source of precipitation in watershed modelling. However, precipitation measurements frequently are scarce such that the observation network may not fully capture the precipitation events and completely demonstrate the spatial variability of precipitation. Moreover, the precipitation stations are often distributed unevenly in the space, and interpolation techniques are often invoked to provide the necessary input data for the hydrological models in question. Some studies have found that runoff-generation is highly sensitive to the spatial and temporal variability of precipitation data, which is the main source of input data uncertainty in rainfall-runoff models (Smith, 2004). In this study, three types of precipitation input (Thiessen polygon, IDW surface grid and TPS surface grid) are applied in the Chaohe basin in northern China, and three lumped, surface hydrologic model (GR4J, IHACRES, and Sacramento) are selected to study the accuracy and predictive uncertainty of these three types of precipitation interpolation on daily streamflow.

\section{STUDY AREA}

The Chaohe watershed is an important headwater of Miyun Reservoir, supplying $70 \%$ of drinking water to Beijing and surrounding townships (population $>19$ million), and around $60 \%$ of the water in Miyun Reservoir originates from the Chaohe watershed (Sun et al., 2008). The climate of the watershed belongs to the temperate continental monsoon type that has the semi-arid characteristics. The watershed $\left(\mathrm{E} 116^{\circ}-118^{\circ}, \mathrm{N} 40^{\circ}-42^{\circ}\right)$ drains an area of $5340 \mathrm{~km}^{2}$. Elevation ranges from $121 \mathrm{~m}$ to $2206 \mathrm{~m}$ (Figure 1), and $80 \%$ of the watershed is mountainous. There are three hydrological stations in the catchment. The hydrologic model is calibrated from data for the three sub-basins, described as basin1, basin2 and basin 3 from upstream to downstream; basin2 includes basin 1; basin 3 includes basin 1 and basin2. The upstream watershed for basin 3 gauge outlet represents the whole Chaohe basin.

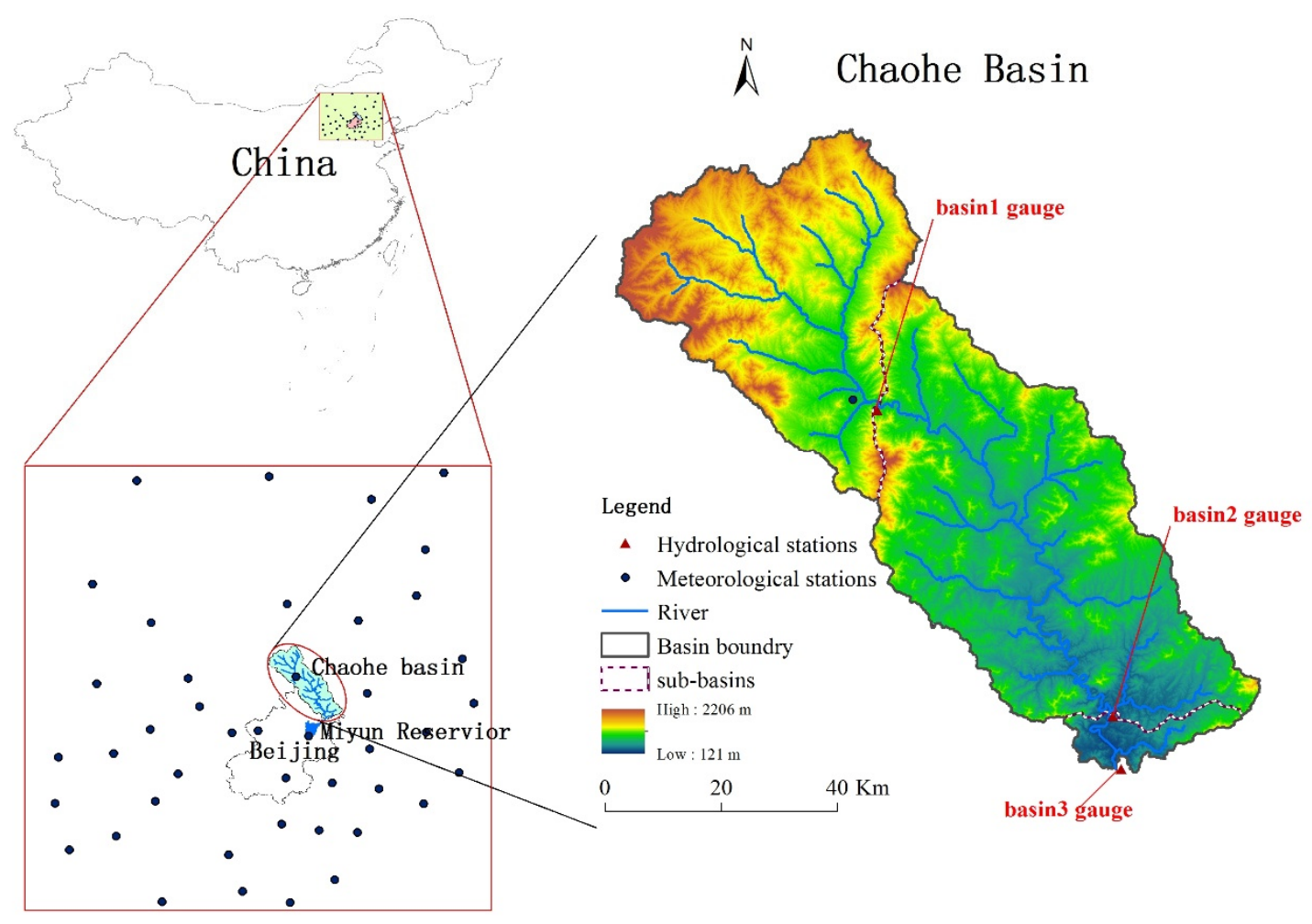

Figure 1. Location of the Chaohe basin, China. 


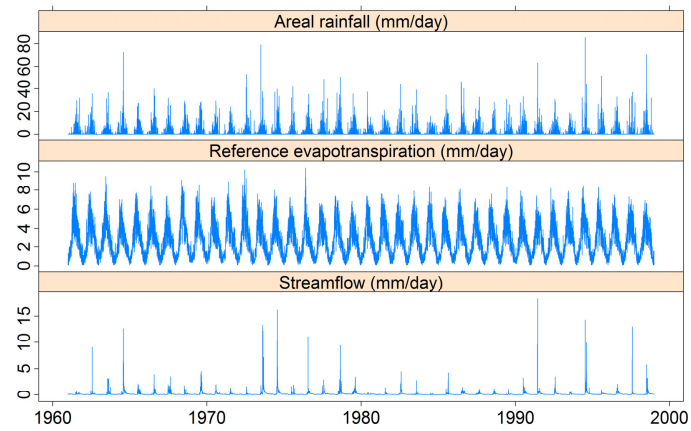

Figure 2. Rainfall( $\mathrm{P})$, reference evapotranspiration(E) and streamflow $(\mathrm{Q})$ of Chaohe basin

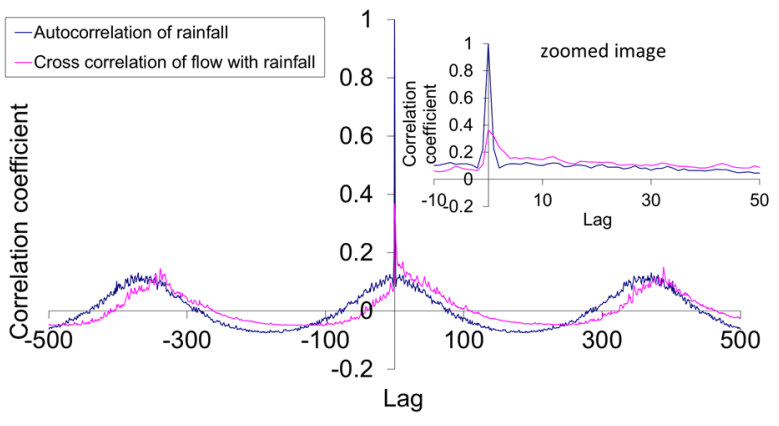

Figure 3. Correlation analysis of rainfall and streamflow for Chaohe basin

Figure 2 depicts the time series of Rainfall (P), reference evapotranspiration (E) and streamflow (Q) of Chaohe basin. Figure 3 shows a correlation analysis of rainfall and streamflow for the Chaohe basin. The autocorrelation in the rainfall shows that it possesses a strong seasonality. The pattern near lag=0 shows there is little persistence in rainfall from one day to the next (there is an only slightly higher correlation coefficient at lag=1 than all subsequent values). The cross correlation between rainfall and streamflow gives some insight into the catchment response. There is a lag of approximately 1 month in the cross correlation peak near lag=365, indicating that the catchment takes about 1 month to significantly respond to the onset of the wet season. In addition, the seasonality in the streamflow has a smaller amplitude than the seasonality in the rainfall, indicating the impact of a significant baseflow response, and/or a limited impact of evaporation on seasonality. The peak of the cross correlation function is at lag $=0$, though there is a significant enhancement in the correlation coefficient at lag $=1$, indicating that the delay in the peak of the streamflow response compared to the rainfall is between 0 and 1 days. This is further emphasised in the Fourier deconvolution of these correlation functions, which shows a comparable response at a lag of 1 day. A successful rainfall-runoff model will need to reproduce these features.

\section{INTERPOLATION METHODS AND MODELS}

\subsection{Thiessen polygon (THI)}

Thiessen polygon (THI) estimates areal precipitation values by dividing catchment area into polygons so that each polygon contains a single sample point (Chow and Chow, 1964; Thiessen, 1911). Each interpolated point assigns the value equal to the closest sample point. The THI approach has the merit of simplicity, but it ignores information on neighbouring points and does not create a continuous precipitation surface. With this approach, dynamic Thiessen polygons were created over the study region due to missing data during the study period.

\subsection{Inverse Distance Weighting (IDW)}

Inverse Distance Weighting (IDW) estimates the interpolation values based on the assumption that everything is related to everything else, but near things are more related than distant things. The value at an unknown point can be approximated by a weighted sum of the value of $n$ known points. The weights used for averaging are a decreasing function of the distance between the known and unknown points (Philip and Watson, 1982). The general equation for IDW is:

$$
P_{x}=\sum_{i=1}^{n} \lambda_{i} P_{i}
$$

where $P_{x}$ represents the interpolated rainfall in the point $x, \lambda_{i}$ is a weight assigned to the station $i$ and $P_{i}$ is the observed precipitation for the station $i$. The weights are calculated as follows:

$$
\lambda_{i}=\frac{d_{i}^{-\alpha}}{\sum_{i=1}^{n} d_{i}^{-\alpha}}
$$

where $d_{i}$ is the distance from each station to the unknown site, and $\alpha$ is a power exponent. The power variable controls the significance of the surrounding points upon the interpolated value. A higher power tends to give larger weights to nearest points and increasingly less weights to distant points, and vice versa. Relevant studies have found that using a power value of 1 for yearly time steps, 2 for daily and monthly time steps and 3 for hourly time step can minimize the interpolation errors (Ly et al. 2011). In this paper, the $\alpha$ value was set to 2, 
a value that is the most widely used for daily and monthly precipitation interpolation. The search radius can be defined by the range of a fixed number of closest points. The search radius used is 43 points in this study.

\subsection{The thin plate spline (TPS)}

The thin plate spline (TPS) technique interpolates precipitation as a function of latitude, longitude, and elevation and can model the effect of topography. In this study, ANUSPLIN4.4 (Hutchinson and Xu, 2013) was used to interpolate precipitation. The grids had a cell size of 0.01 degree $\times 0.01$ degree (approximately 1 $\mathrm{km} \times 1 \mathrm{~km}$ ) and were combined with a DEM with the same resolution. The DEM used here to interrogate the final climate grid products was rebuilt from Global Multi-resolution Terrain Elevation Data 2010 (GMTED2010) 7.5-arc-second dataset using ANUDEM5.3 (Hutchinson, 2011). GMTED2010 is the latest and possibly the best global terrain product to date. It is close to a real DEM rather than a canopy top surface as found in some satellite terrain products. A rebuilt 1-km resolution DEM will suppress sharp terrain features, which may be mapping errors, on the resulted climate surface grids and facilitate creating climate grids with more realistic spatial distribution patterns.

The ANUSPLIN package, developed using a thin plate smoothing spline algorithm, contains FORTRAN programs for fitting (interpolating) surfaces to noisy data, in particular to climate data. It fits a surface to noisy multivariate data as functions of one or more independent variables.

The partial spline model for $\mathrm{N}$ observed data values $z_{i}$ at positions $x_{i}$ is given by:

$$
z_{i}=f\left(x_{i}\right)+\sum_{j=1}^{p} \beta_{j} \Psi_{j}\left(x_{i}\right)+\varepsilon_{i}, \quad(i=1, \cdots, n ; j=1, \cdots, p),
$$

where $f$ is an unknown smoothing function of $x_{i}, \Psi_{j}$ are a set of p-dimensional function of independent covariates, $\beta_{j}$ are a set of unknown p-dimensional parameters of coefficients of the $\Psi_{i}$, and each $\varepsilon_{i}$ is an independent, zero mean error term with covariance structure given by:

$$
E\left(\varepsilon \varepsilon^{T}\right)=V \sigma^{2},
$$

where $\varepsilon=\left(\varepsilon_{1}, \cdots, \varepsilon_{n}\right)^{T}, V$ is a positive definite $\mathrm{n} \times \mathrm{n}$ matrix and $\sigma^{2}$ may be known or unknown. The errors $\varepsilon_{i}$ are uncorrelated if $V$ is diagonal and correlated otherwise (Hutchinson, 1995).

Precipitation is greatly affected by topography. Hutchinson (1998) found that the interpolating accuracy of a precipitation surface would be enhanced significantly with a continuous, spatially varying, dependence on appropriately scaled elevation (Hutchinson, 1995, 1998a and b).

The thin plate spline (TPS) technique has been applied in a number of studies and has proven to be one of the best techniques for interpolating precipitation (Arowolo et al. 2017). In this study, the TPS interpolation used the same rain-gauge stations as other interpolation methods.

\subsection{Rainfall runoff models}

We used three well-known conceptual rainfall-runoff models with different complexities from 4 to 13 parameters (Table 1). In the GR4J model (Perrin et al. 2003), the storage of rainfall, evapotranspiration and percolation in the surface soil are controlled by the production store, and the routing of effective rainfall is controlled by the routing store. In the routing store, the quick flow is generated by $10 \%$ of the effective rainfall, and the slow flow is generated using $90 \%$ of effective rainfall (Le Moine et al, 2008). The GR4J model has been applied in various studies (Brigode et al, 2013).

The IHACRES model has many versions, used in various studies (Post et al. 2012). We used the catchment moisture deficit (CMD) version (Croke and Jakeman, 2004) as it has more physical meaning for the parameters. There are two stores in the IHACRES model: the nonlinear store for the generation of effective rainfall using a nonlinear function to deal with the raw rainfall and using accounting equations to calculate the CMD output, and the linear store to convert effective rainfall into quick and slow flow using unit hydrographs.

The Sacramento model has five runoff components: direct runoff from an impervious area, surface runoff, interflow, supplementary base flow and primary base flow. We used a 13 instead of 16 parameter version of the Sacramento model (Burnash et al. 1973). Briefly, excess rainfall becomes runoff through a unit hygrograph, and the rest of the rainfall fills various depths of soil moisture stores, which are interconnected. Loss through evapotranspiration happens at the soil stores, and the rest of the water becomes interflow and groundwater. The summation of the surface and lateral flow become streamflow. The Sacramento model has been used in many studies (Petheram et al. 2012).

Table 1 gives descriptions of the parameters of the three rainfall-runoff models. We used the hydrologic 
Guo et al., A comparative analysis of precipitation estimation methods for streamflow prediction

models, objective functions and calibration algorithms in the Hydrological Model Assessment and Development (Hydromad; Andrews et al. 2011) modelling package, which is an open-source software package in R. The Hydromad package is available at http://hydromad.catchment.org.

Table 1. Parameters for each model.

\begin{tabular}{|c|c|c|c|c|}
\hline $\begin{array}{l}\text { Parameter } \\
\text { name }\end{array}$ & $\begin{array}{l}\text { Paramete } \\
\text { r No. }\end{array}$ & Unit & Range & Description \\
\hline \multicolumn{5}{|l|}{ GR4J } \\
\hline $\mathrm{X} 1$ & 1 & $\mathrm{~mm}$ & $100-1,200$ & Maximum capacity of the production store \\
\hline $\mathrm{X} 2$ & 2 & $\mathrm{~mm}$ & $-5-3$ & Groundwater exchange coefficient \\
\hline $\mathrm{X} 3$ & 3 & $\mathrm{~mm}$ & $20-300$ & 1-day-ahead maximum capacity of the routing store \\
\hline $\mathrm{X} 4$ & 4 & day & $1.1-2.9$ & Time base of the unit hydrograph, UH1 \\
\hline \multicolumn{5}{|c|}{ IHACRES-CMD } \\
\hline $\mathrm{f}$ & 1 & - & $0.5-1.5$ & CMD stress threshold as a proportion of $d$ \\
\hline $\mathrm{e}$ & - & - & $0.9-1.3$ & Temperature to potential evapotranspiration (PET) conversion factor \\
\hline $\mathrm{d}$ & 2 & $\mathrm{~mm}$ & $200-550$ & CMD threshold for producing flow \\
\hline$\tau_{\mathrm{s}}($ tau_s $)$ & 3 & day & $30-600$ & Time constant for slow flow store \\
\hline$\tau_{q}($ tau_q $)$ & 4 & day & $1-10$ & Time constant for quick flow store \\
\hline$v_{\mathrm{s}}\left(\mathrm{v} \_\mathrm{s}\right)$ & 5 & - & $0.1-1$ & Fractional volume for slow flow \\
\hline \multicolumn{5}{|c|}{ Sacramento } \\
\hline UZTWM & 1 & $\mathrm{~mm}$ & $1-150$ & Upper zone tension water maximum capacity \\
\hline UZFWM & 2 & $\mathrm{~mm}$ & $1-150$ & Upper zone free water maximum capacity \\
\hline $\mathrm{UZK}$ & 3 & $1 /$ day & $0.1-0.5$ & Upper zone free water lateral depletion rate \\
\hline PCTIM & 4 & - & $0.000001-0.1$ & Fraction of the impervious area \\
\hline ADIMP & 5 & - & $0-0.4$ & Fraction of the additional impervious area \\
\hline ZPERC & 6 & - & $1-250$ & Maximum percolation rate coefficient \\
\hline REXP & 7 & - & $0-5$ & Exponent of the percolation equation \\
\hline LZTWM & 8 & $\mathrm{~mm}$ & $1-500$ & Lower zone tension water maximum capacity \\
\hline LZFSM & 9 & $\mathrm{~mm}$ & $1-1,000$ & Lower zone supplementary free water maximum capacity \\
\hline LZFPM & 10 & $\mathrm{~mm}$ & $1-1,000$ & Lower zone primary free water maximum capacity \\
\hline LZSK & 11 & $1 /$ day & $0.01-0.25$ & Lower zone supplementary free water depletion rate \\
\hline LZPK & 12 & $1 /$ day & $0.0001-0.25$ & Lower zone primary free water depletion rate \\
\hline PFREE & 13 & - & $0-0.6$ & Fraction percolating from upper to lower zone free water storage \\
\hline
\end{tabular}

\subsection{Precipitation Station Density}

As shown in Figure 1, the density of precipitation stations is variable over the region, which could potentially impact the result. The Kernel Density ("KD") function is adopted to create a smooth surface evaluating the density of precipitation stations. The KD function calculates the density of features in a neighbourhood around those features and expresses the result as magnitude per unit area (Szcześniak and Piniewski 2015). The density map of precipitation stations is generated using the kernel density estimation provided

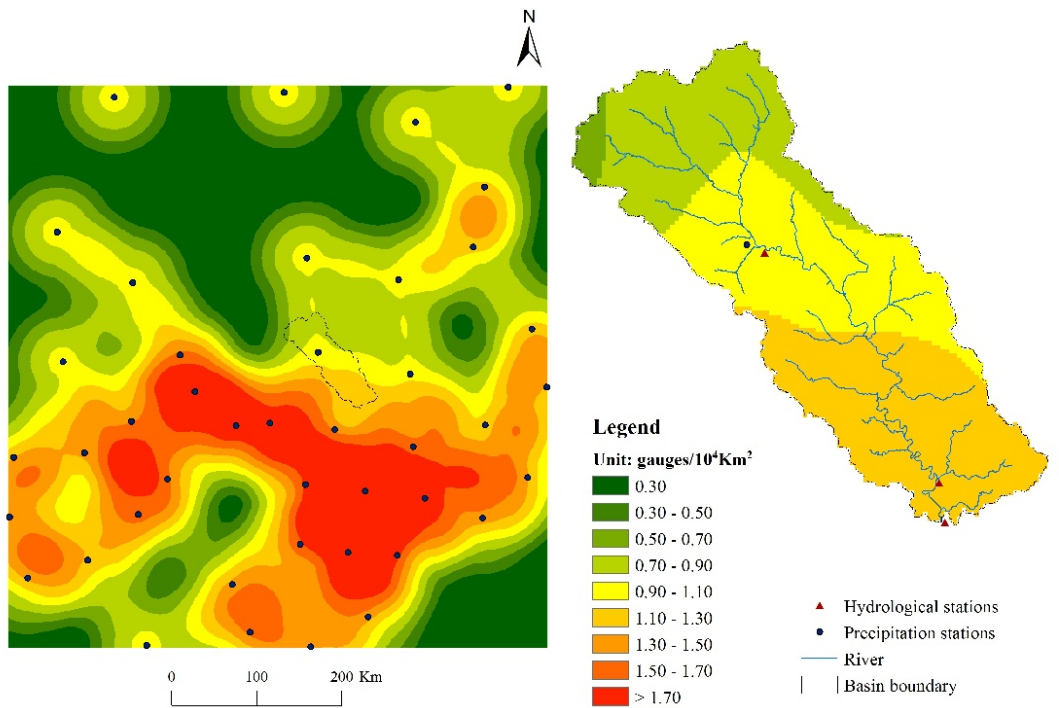

Figure 4. Density map of precipitation over the region (units: gauges per $\mathrm{km}^{2}$ ) 
by ArcGIS Spatial Analyst (ESRI, 2012). The search radius is set to $100 \mathrm{~km}$ and the population field is set to none. The low density (particularly in the north) results in local 'hot spots' in the density map.

The mean density of precipitation station (units: gauges per $10^{4} \mathrm{~km}^{2}$ ) in each sub-basin is 0.87 (basin1), 1.00 (basin2) and 1.01 (basin3) expressed in units (number of stations per $\mathrm{km}^{2}$ ). Compared to basin2 and basin3, the density of precipitation stations in basin1 is relatively sparse.

\subsection{Model performance criteria}

The Nash-Sutcliffe efficiency (NSE; Nash and Sutcliffe 1970), a form of mean squared error, is widely used in hydrology as a criterion of hydrologic model performance and was often used as an objective function. The range of NSE is $(-\infty, 1]$, where 1 represents a perfect match between the observed and simulated flow. The NSE objective function focuses on fitting high flows (Krause et al. 2005). Here, it was also computed in terms of square root transformed flows (noted NSEsq hereafter), which make is it possible to assess model efficiency for both high and low-to-medium flows.

The optimisation evolutionary technique used to calibrate parameter values is the Shuffled Complex Evolution (SCE; Duan et al, 1992) algorithm, one of the popular methods for parameter calibration. The SCE algorithm with global search has proved to be both effective and relatively efficient and provides similar performance to other evolutionary optimization algorithms (Shin et al. 2013). The value of the objective function for calibration of parameters can be used as model performance statistics.

\section{RESULTS}

The performance of all models applied to basin 1 are poor, with NSEsq ranging between 0.39 and 0.53 . The overall best performance was obtained using IDW estimated areal rainfall as input to the Sacramento model (average NSEsq value was 0.53 ), though IHACRES using ANUSPLIN was only slightly lower at 0.48 , and GR4J using Thiessen gave 0.46 . The reason for the poor performance for basin 1 may be due to the low density of rain-gauge stations in basin 1 as described above. For basin2, all models performed best using ANUSPLIN derived areal rainfall, with NSEsq $=0.68$ for the IHACRES and Sacramento models, and 0.58 for the GR4J model (averaged across all calibration periods). A similar result is found for basin3 (all models performing slightly better when using ANUSPLIN derived areal rainfall), with IHACRES performing slightly better than the other models (average NSEsq values were: 0.68 (IHACRES), 0.59 (GR4J) and 0.66 (Sacramento)).

Overall, the model performance in basin1 is not as good as basin2 and basin3; the ANUSPLIN surface interpolation performed the best overall under various combinations of conditions. The IDW surface also performs well in the upper and middle basin but the Thiessen polygon is inferior to the other two methods. In regard to the hydrologic models, IHACRES and Sacramento perform better than GR4J for these basins, while the combination of ANUSPLIN with IHACRES perform the best, with the Sacramento model a close second.

For IHACRES, all areal rainfall estimation methods yield similar parameter values for model parameters $f, v_{\mathrm{s}}$ and $\tau_{\mathrm{s}}$. For parameter $\tau_{\mathrm{s}}$, areal rainfall estimated using ANUSPLIN yields a much smaller range in values than that using IDW or Theissen polygon methods. There is a significant difference between basins in the parameter values for $v_{\mathrm{s}}$ and $\tau_{\mathrm{s}}$, with basin 1 having a significant higher calibrated value for both parameters. A similar pattern is seen when using GR4J: one of the parameters has a smaller variability in calibrated $r$ value for different calibration periods when using areal rainfall estimated by ANUSPLIN. The other parameters show comparable variability between the different areal rainfall estimation methods. The situation when using the Sacramento model is different. Some parameters show greater variability when using ANUSPLIN derived areal rainfall (e.g. LZFSM and LSFPM), while others show greater variability when using Thiessen Polygon derived areal rainfall (e.g. UZTWM).

\section{CONCLUSIONS}

The ANUSPLIN surface interpolation performs the best overall under various combinations of conditions. The IDW surface also performs well in the upper and middle basin but the Thiessen polygon is inferior to the other two methods; as to hydrologic models, IHACRES and Sacramento perform better than GR4J; the combination of ANUSPLIN with IHACRES performs the best. The parameter analysis of IHACRES and GR4J models shows some of its calibrated parameters yield a much smaller range in variability using ANUSPLIN derived areal rainfall. Further studies will be concentrated on sensitivity and uncertainty analysis of these models.

\section{ACKNOWLEDGEMENTS}

This work was supported by the National Natural Science Foundation of China (No. 41271004). 
Guo et al., A comparative analysis of precipitation estimation methods for streamflow prediction

\section{REFERENCES}

Andrews, F.T., B.F.W. Croke and A.J. Jakeman (2011). An open software environment for hydrological model assessment and development. Environmental Modelling \& Software, 26(10), 1171-1185.

Arowolo, A.O., Bhowmik, A.K., Qi, W. and Deng, X. (2017). Comparison of spatial interpolation techniques to generate high-resolution climate surfaces for Nigeria. International Journal of Climatology, doi:10.1002/joc.4990.

Brigode, P., L. Oudin and C. Perrin (2013). Hydrological model parameter instability: A source of additional uncertainty in estimating the hydrological impacts of climate change? Journal of Hydrology, 476, 410-425.

Burnash, R.J., R.L. Ferral and R.A. McGuire (1973). A generalized streamflow simulation systemConceptual modeling for digital computers. Joint Federal-State River Forecast Center Tech. Rep., Department of Water Resources, State of California and National Weather Service.

Chow, V.T. and V. Te Chow (1964). Handbook of applied hydrology: a compendium of water-resources technology. New York, McGraw-Hill Book Co., sec, 7, 47-48.

Croke, B. and A.J. Jakeman (2004). A catchment moisture deficit module for the IHACRES rainfall-runoff model. Environmental Modelling and Software, 19(1), 1-5.

Duan, Q., S. Sorooshian and V. Gupta (1992). Effective and efficient global optimization for conceptual rainfall-runoff models. Water Resources Research, 28(4), 1015 - 1031.

ESRI, (2012). Arc GIS desktop: release 10.1. Environmental Systems Research Institute: Redlands, California.

Hutchinson, M.F. (1995). Interpolating mean rainfall using thin plate smoothing splines. International Journal of Geographical Information Systems, 9(4), 385-403.

Hutchinson, M.F. (1998a). Interpolation of rainfall data with thin plate smoothing splines. Part I: Two dimensional smoothing of data with short range correlation. Journal of Geographic Information and Decision Analysis, 2(2), 139-151.

Hutchinson, M.F. (1998b). Interpolation of rainfall data with thin plate smoothing splines. Part II: Analysis of topographic dependence. Journal of Geographic Information and Decision Analysis, 2(2), 152-167.

Hutchinson, M.F., (2011). ANUDEM version 5.3 User Guide. Canberra: Fenner School of Environment and Society, Australian National University.

Hutchinson, M.F. and T. Xu (2013). ANUSPLIN version 4.4 User Guide. Canberra: Fenner School of Environment and Society, Australian National University.

Krause, P., D.P. Boyle and F. B Se (2005). Comparison of different efficiency criteria for hydrological model assessment. Advances in Geosciences, 5, 89 - 97.

Le Moine, N., V. Andréassian and T. Mathevet (2008). Confronting surface- and groundwater balances on the La Rochefoucauld-Touvre karstic system (Charente, France). Water Resources Research, 44(3), doi:10.1029/2007WR005984.

Ly, S., C. Charles and A. Degré (2011). Geostatistical interpolation of daily rainfall at catchment scale: the use of several variogram models in the Ourthe and Ambleve catchments, Belgium. Hydrology and Earth System Sciences, 15(7), 2259-2274.

Nash, J.E. and J.V. Sutcliffe (1970). River flow forecasting through conceptual models part I - A discussion of principles. Journal of Hydrology, 10(3), 282-290.

Perrin, C., C. Michel and V. Andréassian (2003). Improvement of a parsimonious model for streamflow simulation. Journal of Hydrology, 279(1-4), 275-289.

Petheram, C., Rustomji, P., Chiew, F.H.S. and Vleeshouwer, J. (2012). Rainfall-runoff modelling in northern Australia: A guide to modelling strategies in the tropics. Journal of Hydrology, 462-463, 28-41.

Philip, G.M. and D.F. Watson (1982). A precise method for determining contoured surfaces. The APPEA Journal, 22(1), 205-212.

Post, D.A., Chiew, F.H.S., Teng, J., Viney, N.R., Ling, F.L.N., Harrington, G., Crosbie, R.S., Graham, B., Marvanek, S. and McLoughlin, R. (2012). A robust methodology for conducting large-scale assessments of current and future water availability and use: A case study in Tasmania, Australia. Journal of Hydrology, 412-413, 233-245.

Smith, M.B., Koren, V.I., Zhang, Z., Reed, S.M., Pan, J.J. and Moreda, F. (2004). Runoff response to spatial variability in precipitation: an analysis of observed data. Journal of Hydrology, 298(1-4), 267-286.

Sun, N., Li, X.B., Li, Z.J. and Yu, X.X. (2008). Simulation of impacts of changes in land use and cover on annual streamflow in the upper reach of Chaohe River Basin. Beijing Linye Daxue Xuebao/Journal of Beijing Forestry University, 30(SUPPL. 2), 22-30.

Szcześniak, M. and M. Piniewski (2015). Improvement of Hydrological Simulations by Applying Daily Precipitation Interpolation Schemes in Meso-Scale Catchments. Water, 7(2), 747-779.

Thiessen, A.H. (1911). Precipitation averages for large areas. Monthly weather review, 39(7), 1082-1089. 